\title{
O LAZER COMO POSSÍVEL ESPAÇO/TEMPO PARA O CONSUMO DE DROGAS
}

Recebido em: 26/01/2011

Aceito em: 01/11/2011

\author{
Daniella Marchese ${ }^{1}$ \\ Guanis de Barros Vilela Junior ${ }^{2}$ \\ Universidade Metodista de Piracicaba - UNIMEP \\ Piracicaba - SP - Brasil \\ Afonso Antônio Machado ${ }^{3}$ \\ Universidade Estadual Paulista - UNESP \\ Rio Claro - SP - Brasil
}

RESUMO: Por ser o lazer, momento de vivências onde há possibilidade de liberação das tensões cotidianas e ao mesmo tempo, espaço criativo e questionador, surge a possibilidade de identificar a presença da droga neste espaço/tempo, como instrumento viabilizador destas atitudes. A presença das drogas nas mais diversas sociedades, comumente abordada através da perspectiva fisiológica e psicológica, não parece considerar o importante aspecto deste fenômeno, enquanto manifestação social e cultural. Através do olhar biopsicossocial, faz-se possível reavaliar tanto usuários quanto o próprio uso da droga e tentar encontrar, mais do que respostas, um panorama desta presença em nossa cultura.

PALAVRAS CHAVE: Atividades de Lazer. Comportamento de Procura de Droga. Sociedades.

\section{LEISURE AS POSSIBLE SPACE/TIME FOR THE USE OF DRUGS}

ABSTRACT: To be the leisure, time of experiences where have the possibility of the release of daily tensions and at the same time, space creative and inquisitive, the possibility of identifying the presence of drugs in this space/time arises, as an instrument enabler of these processes. The presence of drugs in various societies, commonly addressed by physiological and psychological perspective, does not seem to consider the important aspect of this phenomenon, while social and cultural manifestation. Through the biopsychosocial look, it is possible to reassess both users

\footnotetext{
${ }^{1}$ Mestre em Educação Física, área de Movimento Humano, Cultura e Educação, mestrado concluído com apoio da CAPES / Prosup.

${ }^{2}$ Professor da Universidade Metodista de Piracicaba - UNIMEP / Campus Taquaral, FACIS.

3 Professor da Universidade Estadual Paulista - UNESP / Campus Rio Claro, Departamento de Educação Física - IB.
} 
and the own use of drugs, trying to find more than answers, an overview of this presence in our culture.

KEYWORDS: Leisure Activities. Drug-Seeking behavior. Societies.

Nos séculos XIX e XX, Sigmund Freud, acreditando ter descoberto possibilidades de aplicação terapêutica em um alcalóide de potente ação estimulante, receitou cocaína para tratar o vício em morfina de seu amigo Fleischl. O amigo morreu em decorrência do então "medicamento", e mesmo observando este quadro, Freud talvez não tivesse notado que seu grau de envolvimento pessoal com a droga não era unicamente científico. (BURNS, 2002; GURFINKEL, 2008). Os estudos e o conhecimento formalizado sobre as drogas evoluíram drasticamente desde então. No entanto, mesmo com o fracasso freudiano e a evolução dos estudos no sentido de erradicar a droga, sua presença ainda hoje é recorrente entre as diversas classes sociais, seja para uso ou comercialização. Para justificar o paradoxo da evolução dos estudos e da persistente presença da cocaína na sociedade, usuários dizem do tédio, do marasmo de quem tem tudo que podia almejar e busca novas emoções em experiências limítrofes. Dizem da busca por algo que no cotidiano não se alcança, não se pode vivenciar. Dizem da miséria e do desemprego de quem encontrou no tráfico, uma chance para poder sustentar não apenas a si próprio, mas também sua família, seus dependentes. Estaria na busca de um lazer associado ao prazer inconseqüente, o caminho que leva o usuário ao vício? Estaria no desprazer de um lazer capitalizado a presença da droga como fuga daquilo que não se pode ter? Estaria na falta de perspectiva (e então perpassando conceitos importantes e básicos como educação e saúde), a presença onipotente da droga na cultura de um país? 
Antes de traçar as possibilidades de lazer enquanto espaço/tempo para o consumo de drogas, é preciso compreender a estrutura social sob a perspectiva deste estudo. Para cada mudança social, então entendendo a sociedade de forma contextualizada, podem-se conseqüentemente observar mudanças no comportamento dos seus atores sociais. Apontando neste sentido, para tentar explicar a construção dos aspectos fundamentais desta sociedade, explica Elias, (2000, p.5):

[...] a sociedade ocidental procura descrever em que constituí seu caráter especial e tudo aquilo de que se orgulha: o nível de sua tecnologia, a natureza de suas maneiras (costumes), o desenvolvimento de seu conhecimento científico ou visão de mundo, e muito mais.

A idéia da "dinâmica social" segundo a leitura de Elias caminha para a verificação de uma sociedade que cresce e baseia-se nos sentimentos próprios do que se entende, por civilidade. De acordo com o autor a sociedade que surge desta dinâmica, é marcada por sentimentos “crescentes de vergonha e repugnância, em concomitância com uma maior tendência a esconder, nos bastidores da vida social, aquilo que as causa". (ELIAS, 2000 apud LANDINI, 2005, p. 2).

Desta relação entre ator e sociedade àquilo que não causa mudança do ator social por si só, de acordo com o que transparece socialmente como correto e aceitável, pode ter normas e regras controladas pelo próprio Estado. Aquilo que inicialmente poderia ser entendido como repressão e violência passa, ao longo dos anos e do crescimento desta estrutura social, a ser incorporado como "costume", possivelmente transformado em um traço cultural da sociedade em questão.

Não se trata, no entanto de uma redução processual sociológica. Segundo Landini (2005, p.6), é possível compreender melhor a preocupação ao definir sociedade e seu caminho contextual em Norbert Elias: 
$\mathrm{Na}$ sociologia, a redução processual pode ser vista em distinções conceituais entre o "ator" e sua atividade, entre estruturas e processos, objetos e relações. Conceitos tais como normas, valores, papéis, classe social, etc., muitas vezes parecem existir independente dos indivíduos, o que, para Elias, é inapropriado.

Este inapropriado diz respeito especificamente ao compreender que tal sociedade, inevitavelmente composta por indivíduos, não pode ser entendida nem ser sustentada se não for concebida de forma plural. Ou seja, esta sociedade na qual se insere o lazer neste estudo, deve ser compreendida através de relações constituintes e base de sua construção e crescimento. E desta mesma forma, os sujeitos que figuram tais relações.

Ainda que o lazer não seja uma invenção da sociedade contemporânea, nela seu conceito apresenta-se, não como acessório ou prêmio para a produção e recompensa do trabalho. O lazer neste prisma é manifestação própria do indivíduo, pelo prazer que está inserido nestas vivências, e não em detrimento de outras atividades que o complementam ou são necessárias para proporcionar tais manifestações.

Ao inicarmos um diálogo abordando lazer e consumo de drogas, é necessário compreender algumas características específicas do lazer. Para tanto, o estudo apropriase de uma das reflexões mais importantes na compreensão desta questão. Segundo Marcellino (1998, p. 53):

A questão do lazer é marcada pela ambigüidade: pode contribuir para o desenvolvimento de atitudes críticas e criativas com relação às esferas pessoal e social, ou, simplesmente, acentuar o conformismo, levando a processos de acomodação.

Como, no entanto, a questão do lazer aparece neste estudo intrinsecamente relacionada à questão social, onde o espaço e o tempo de lazer irão figurar como uma das possibilidades para o consumo de drogas deve-se compreender com maior 
entendimento essa esfera de vivências sob um prisma mais amplo. Ainda em Marcellino, (2007), é possível verificar mais profundamente esta questão, na qual lazer e sociedade relacionam-se como "[...] cultura vivenciada (praticada, fruída ou conhecida), no tempo disponível das obrigações profissionais, escolares, familiares, sociais, combinando os aspectos tempo e atitude [...]".

E desta relação, surge à possibilidade de compreendermos o diálogo do espaço/tempo de lazer através do contexto onde o mesmo encontra-se, como prossegue Marcellino (2007), ao colocar que "[...] o lazer gerado historicamente e dele podendo emergir, de modo dialético, valores questionadores da sociedade como um todo, e sobre ele também sendo exercidas influências da estrutura social vigente”.

Diálogo esse que pode constituir-se como caminho para uma redefinição do que se compreende, limitadamente, sobre a importância destas vivências de lazer na estrutura social e inclusive educacional, ainda segundo Marcellino (2007, p.3):

[...] um tempo que pode ser privilegiado para vivência de valores que contribuam para mudanças de ordem moral e cultural, necessárias para solapar a estrutura social vigente; portador de um duplo aspecto educativo - veículo e objeto de educação, considerando-se, assim, não apenas suas possibilidades de descanso e divertimento, mas também de desenvolvimento pessoal e social.

Deve-se considerar mais atentamente a questão dialética desses valores. Ao emergir como um diálogo questionador entre o lazer e a sociedade vigente, o lazer traz consigo, além da inserção historicamente situada, (e que conseqüentemente permeia aspectos de toda a esfera social onde ele se encontra), o espaço fértil para a manifestação de aspectos desta sociedade, subjugados em outras perspectivas do contexto histórico no qual se encontra. Marcellino, (2007, p.3) complementa:

A vivência desses valores pode se dar numa perspectiva de reprodução da estrutura vigente, ou da sua denúncia e anúncio - através da vivência 
de valores diferentes dos dominantes - imaginar e querer vivenciar uma sociedade diferenciada.

Ao abordar o lazer neste sentido, se aceita a possibilidade de valorações diversas e diferentes daquelas consideradas como comportamento desejável e dirigido para tais momentos. O lazer não é só aceito na sociedade contemporânea, como sob determinada ótica, muito bem-vindo. Passou a ser meio de produção riquíssima de valores e também meio de produção, de consumo. O caminho do lazer contemporâneo é vasto de possibilidades para o enriquecimento da cultura e sua propagação fértil, mas muito comumente podemos verificar o uso deste espaço/tempo de lazer com intuitos diferenciados dos usualmente entendidos como atividades de lazer. No entanto o fenômeno cultural tem muito mais de consumista do que citou Adam Smith ${ }^{4}$, quando entendeu ser o capitalismo o valor dos indivíduos que buscam seus interesses próprios, opostamente ao entendimento de servir o bem comum. Ainda que intermediado por iniciativas de cunho cultural e educativo, o lasseiz-fare ${ }^{5}$ produzido pela máquina consumista da sociedade capitalista atual impera. E neste estereotipo de lazer de consumo, podemos identificar características específicas dos atores sociais. Riesman (1975, p. 312), identificou três tipos específicos de sujeitos sociais, que colaboram para um caminho na compreensão deste lazer contemporâneo:

Os ajustados são[...] aqueles que correspondem em sua estrutura de caráter, às exigências de sua sociedade ou classe social [...] os que não se conformam com o padrão caracteriológico dos ajustados podem ser anômicos ou autônomos. Anômico é a tradução de anomique, de Durkheim, ou seja, sem regras, desgovernado [...] Os autônomos são aqueles que, no todo, são capazes de se conformarem às normas comportamentais de sua sociedade - uma capacidade que falta em geral nos anômicos - mas que são livres de escolher entre se conformarem ou não.

\footnotetext{
${ }^{4}$ Adam Smith, 1776, em sua obra "A Riqueza das Nações".

${ }^{5}$ Doutrina segundo a qual caberia aos governos assumirem exclusivamente as funções que apoiassem e estimulassem as atividades lucrativas, e a interferência governamental era proibida nos demais assuntos econômicos. Este liberalismo proporcionou as bases filosóficas do sistema capitalista industrial.
} 
Longe da intenção de rotular os sujeitos desta sociedade do lazer de consumo, podemos verificar com esta colocação de Riesman, (1975), uma tendência questionável. Salvo os extremos, onde o primeiro (ajustado), parece ser o "consumidor" ideal para este lazer produzido e aparentemente de mão única, e o segundo (o anômico), cujo lazer figura como "válvula de escape", onde as vivências passam a ser prêmio para o tempo de trabalho e espaço para consumo fazendo uso do capital produzido por sua mão-deobra, parece-nos existir apenas no autônomo, a flexibilidade e criticidade necessárias para fazer do lazer um espaço fecundo.

No entanto não é possível creditar apenas aos autônomos sociais a possibilidade de desenvolvimento do lazer contemporâneo conceituado como espaço crítico e criativo. Indivíduos em tempo de lazer carregam em si todas as significantes de uma sociedade capitalista que impõe algumas necessidades a serem preenchidas para que seu papel social seja pleno. Enquanto se espera educar para compreensão de que o lazer é espaço/tempo de crítica e criatividade, como elucida Marcellino, temos na contramão desta tendência todos os valores de um meio de produção que determina quem pode o quê. Parker, (1978, p. 31), explica que “[...] a expansão econômica necessitava de homens dispostos e aptos a consumir os produtos e serviços da indústria. Encontrou-se um mercado novo e lucrativo para tais produtos e serviços no lazer das massas populares".

O mesmo trabalhador que terá seu tempo e espaço de lazer, assim mesmo como suas ações dentro deste lazer consumista, determinados por aquilo que pode produzir, será o que irá imediatamente parecer sensível a uma possível inadequação a este sistema. Seu trabalho e salário acabam por intervir em sua maneira de vivenciar o lazer, assim como na de sua família, sejam esposa, filhos, ou qualquer outro dependente de 
sua renda. O produto do trabalho deste ator social, dentro desta estrutura de sociedade, será o mesmo que irá determinar a que "qualidade" de lazer ele e conseqüentemente sua família, terão acesso.

De certa forma, devido à diversidade de fatores que "restringem" este ou aquele ator de uma participação efetiva e descompromissada das vivências do lazer, delineia-se através do produto do trabalho, o perfil do praticante de lazer, e por conseqüência, quais serão suas práticas. E em uma afirmação de Marcellino, (2000, p. 24) fica claro que “[...] a classe social, o nível de instrução, a faixa etária, o gênero, entre outros fatores, limitam as oportunidades de prática do lazer”.

Para que se possa compreender melhor o caminho traçado nesta característica do lazer contemporâneo, podemos fazer uso da proposta de Rojek, (1999). Ao observar o lazer no meio de produção industrial e do trabalho assalariado, o autor apresenta aspectos daqueles que estão excluídos das relações de trabalho idealizadas, por estarem momentaneamente impossibilitados de trabalhar, mas que ainda assim são camadas sociais na estrutura econômica industrial. No entanto, o que não constava daquela conformação social prevista, era a demanda que ao longo do tempo acabaria por ser precursora de um estrato social para o qual não havia mais empregos. E para os quais, a classificação temporária de desemprego, não conformava sua situação na sociedade. Tais trabalhadores buscaram através da produção independente (e compreenda-se aqui, independência por autonomia de produzir seu capital sem estar associado a quaisquer vínculos empregatícios ligados a indústria), passaram a ter acesso ao mesmo lazer daqueles que produziam através dos meios compreendidos como comuns à sociedade onde se inseriam e também a manifestar novas possibilidades de vivenciar este lazer, já que os valores de produção de capital destes indivíduos deixaram de estar associado 
diretamente aos da indústria. Portanto, em sua inadequação junto às camadas sociais previstas, surgem às primeiras manifestações classificadas por Chris Rojek como Classe de Lazer Alternativo. Enquanto outros trabalhadores produziam e consumiam o produto de seu trabalho, através de sua recompensa pelo trabalho, ou seja, o salário, os desempregados desta sociedade ideologicamente estruturada eram sementes de manifestações e novas possibilidades de produção de capital:

Eles rejeitam o trabalho assalariado e a monogamia como opções de estilo de vida viável, muitas vezes são céticos ou hostis aos valores da sociedade "correta", que eles consideram como sendo uma limitação indevida ou pessoalmente prejudicial e eles não possuem capital privado, e voluntariamente trocam a opção do trabalho assalariado e / ou casamento para uma existência sem raízes e, muitas vezes nômade (ROJEK, 1999, p.85). ${ }^{6}$

Porém, não se trata aqui de compreender esta "nova" camada em surgimento com preconceito, tampouco como vítimas desta sociedade. O ponto crucial desta análise está em confrontar os valores desta organização, sendo o trabalho o fator mais importante da vida dos trabalhadores e conseqüentemente, atribuir a idéia lazer como um momento de recompensa, de prêmio pelo trabalho. A comparação com os atores sociais até então compreendidos como desempregados voluntários, ou seja, que momentaneamente figuram sem trabalho, é inevitável. Mas o lazer alternativo citado, traz consigo outras implicações. A princípio por diferenciarem-se daqueles que fomentam sua produção através do vínculo direto à indústria e conseqüentemente por sua autonomia em relação ao trabalho. Circunstancialmente, a expectativa das vivências do lazer em ambos os grupos pode assemelhar-se. No entanto, a autonomia em relação ao meio de produção parece trazer consigo elementos de possibilidades de vivências de

\footnotetext{
${ }^{6}$ Rojek, C. Deviant Leisure: the Dark Side of Free-Time activity. Traduzido por Daniella Marchese, UNIMEP - Universidade Metodista de Piracicaba, 2009.
} 
um lazer também mais autônomo. E nessa esfera do lazer, na qual o trabalho não é mais o ponto alto da vida produtiva do trabalhador, que se inserem valores antinomiais. Rojek (1999, p. 87) afirma que:

É razoável propor que o lazer é um dos espaços indispensáveis para o surgimento e disseminação de valores antinominais. Ao contrário do trabalho, o lazer ocorre em relativamente poucos contextos de vigilância. A cultura incentiva pessoas a relaxarem, dizer o que lhes vem à mente e serem eles mesmos. Evidentemente, o papel da atividade transgressiva na mudança social tem sido muito bem explorado.

Ainda que nos pareça à marca deste lazer "alternativo" ser a criticidade e a criatividade, o que culminaria num processo interessante para maior aproveitamento desse espaço/tempo de lazer, a exploração pela indústria cultural da postura de consumo diretamente atrelada ao prazer necessário para a manifestação do lazer pleno, tem sido crucial para a manutenção e crescimento da idéia de marginalidade como caminho para mudança social. A noção de consumidor ideal acaba traçando indiretamente um perfil daquilo que se espera que seja vivenciado nos momentos de lazer do ator social em conformidade com a estrutura social onde ele está inserido. Portanto, quaisquer manifestações desprendidas daquilo que pode ser entendido como lazer vivido em consenso aos valores da sociedade, tramitam entre a iniciativa de apropriação de um lazer que busca suprir déficits do cotidiano do ator social e aquilo que fica socialmente compreendido como cultura marginal, porque está à margem dos valores sociais. Marginalidade entendida, neste sentido, como característica daquele ator social que, segundo o que se entende por ator inserido na estrutura social, passa a questioná-la e fazer uso de suas divergências como processo para crítica e questionamento desta mesma estrutura. Tal postura faz do espaço/tempo de lazer seu campo fértil de atuação.

Porém, ainda que não inserido neste contexto, o indivíduo que participa desta manifestação do lazer, através das mais diversas apropriações que entende que devam 
ser feitas nesse seu momento de lazer, pode não estar se indispondo aos valores da sociedade capitalista. Pode apenas, em seu conformismo, (e neste ponto retomo a classificação de Riesman (1975), estar conscientemente fazendo uso de seu tempo livre, onde dispõe do capital gerado pelo seu trabalho, para distrair-se da sua cotidianidade. Como nos explica Lefebvre, (1991, p. 82):

Ao se delinear as necessidades, procura-se prevê-las; encurrala-se o desejo. Isso substituiria as auto-regulações espontâneas e cegas do período da concorrência. A cotidianidade se tornaria assim, em curto prazo, o sistema único, o sistema perfeito, dissimulado sobre os outros que o pensamento sistemático e a ação estruturante visam. Nesse sentido a cotidianidade seria o principal produto da sociedade dita organizada, ou de consumo dirigido, assim como sua moldura, a Modernidade.

Parece-nos então, que tais apropriações podem tomar uma proporção importante em alguns momentos do lazer em determinados grupos. E em tais apropriações, podemos nos deparar com as mais diversas ferramentas inseridas neste contexto, sejam elas utilizadas para abarcar uma necessidade subjetiva ou comum ao grupo. É possível aqui, citar passeatas pacíficas e não-pacíficas, pichações, grafite, vestuário, cultos religiosos, depredações, drogas. E tais ferramentas, podem surgir subjetiva ou coletivamente, para confortar, distrair e contestar. Estão presentes em diversas camadas e pelos mais diversos motivos. Parecem encontrar espaço na permissividade de uma sociedade que ameniza suas mazelas também através do lazer e acaba por fazer uso dessas vivências, muito mais do que um espaço frutífero para manifestação cultural e exercício crítico e criativo, momento para dispor de uma liberdade adquirida formalmente, da maneira que entende seu espaço/tempo de lazer. Ao classificar e marginalizar essas atitudes "patológicas" no lazer, o movimento de tentar compreender seus aspectos biopsicossociais, fica comprometido. Já se caminhou intensamente suprindo as lacunas desses questionamentos apenas delegando-as significado 
fisiopatológico. Como interesse principal deste estudo, a droga surge neste contexto, onde tantas outras manifestações inserem-se, porém com o agravante físico pela ação química da droga no organismo do usuário. Estudos no sentido de entender a droga enquanto agente químico, fisiológico e que interfere na saúde do usuário são constantes. Buscar novos olhares nestas significantes pode ajudar a compreender melhor a sociedade em questão.

Marcellino, (1996, p.52), aponta um direcionamento para a presença do risco consentido nas vivências do lazer:

Muitas vezes, por trás desta distinção, vamos encontrar não só preconceitos, mas também manifestações ideológicas que nada mais são do que defesas para não abalar a posição dos dominantes, ou dos pontos de vista de grupos e instituições rançosamente tradicionais [...] Entretanto, mesmo levando em conta toda a carga que essas pressões trazem em si, não se pode deixar de considerar que algumas atividades, levadas a efeito no tempo disponível, não são desejáveis do ponto de vista social porque, vão frontalmente contra os valores de desenvolvimento da pessoa humana nas suas relações.

Ao mesmo tempo, por diversas vezes compactuamos com condutas de valores opostos aos moralmente compreendidos como socialmente aceitáveis e as premiamos. É notório que, numa sociedade que privilegia e premia o melhor, o mais audaz e astuto, o risco, ainda que não transpareça, é muitas vezes motivo de orgulho e prêmio. Em vivências de lazer, podemos sempre permear o risco. Trata-se então de delimitar o "bom e o mau" risco? O risco válido e o risco inválido? E subjetivamente, quais parâmetros usar para identificar o que valorativamente é passível e compreensível, quando se tratam de lazer, sociedade e escolha?

É possível recorrer a La Mendola, (1999, p.73), para compreender melhor esta posição neste questionamento:

As tentativas de afirmação de um EU livre e responsável, passam por recursos que por definição comportam um aumento no nível do perigo. 
É também verdade que, às vezes, esse processo se inscreve em processos de tipo autodestrutivo. Mas o perigo é estruturalmente presente mesmo em muitas práticas que são largamente legitimadas do ponto de vista social.

O estudo do lazer, de suas manifestações e conteúdos, nesta perspectiva, aponta para outra limitação da compreensão destes aspectos. Ainda é possível observar de maneira recorrente, a concepção do lazer de maneira funcionalista. Para tais, o lazer ainda é espaço improdutivo, marginal, inconcebível em uma estrutura social produtiva. E que por diversas vezes acaba sendo impregnado de tensões consentidas, buscadas, para quebrar a rotina impregnada de outras tensões. "Se as tensões devem ser avaliadas, pura e simplesmente, como perturbações das quais as próprias pessoas se procuram ver livres, porque é que no seu tempo de lazer elas voltam sempre a procurar uma intensificação das tensões?" argumentam Elias e Dunning, (1992), levantando um importante questionamento para este estudo.

Fica claro neste ponto, a possibilidade da presença de tensões cotidianas que nos momentos de lazer são aliviadas através de novas tensões. Tais tensões teriam como ser classificadas como boas ou ruins, que não consideradas específicas de cada indivíduo, dentro daquilo que compartilha com outros sujeitos? E tais tensões provocadas, estando inseridas no lazer, (manifestação contida em um panorama social), poderiam se configurar como um caminho fértil para desvelar facetas desta sociedade onde este mesmo lazer se insere?

Para aprofundar a assimilação dos questionamentos propostos através da constatação da existência destas tensões, e para que tais questionamentos possam 
provocar maior reflexão a respeito da possibilidade da presença das drogas nas vivências de lazer, pode-se buscar na conceituação de Caillois ${ }^{7}$, (1990, p.32-33):

Numa extremidade, reina, quase que absolutamente, um princípio comum de diversão, turbulência, improviso e despreocupada expansão, através do qual se manifesta uma certa fantasia contida [...] $\mathrm{Na}$ extremidade oposta, essa exuberância alegre e impensada é praticamente absorvida, ou pelo menos disciplinada, por uma tendência complementar, contrária em alguns pontos, ainda que não em todos, em sua natureza anárquica e caprichosa: uma necessidade crescente de subordinar regras convencionais, imperiosas e incômodas, de cada vez mais a contrariar criando-lhe incessantes obstáculos com o propósito de lhe dificultar a consecução do objetivo desejado. Este se torna, assim, perfeitamente inútil, uma vez que exige um número sempre crescente de tentativas, de persistência, de habilidade ou de artifício.

O interessante, em considerar tais definições, (e inicialmente ampliar a concepção da mesma, propriamente dita), aponta para a possibilidade de a droga surgir neste lazer como parte de tais vivências e encontrar neste espaço, oportunidade e sentido para que aconteça. E sendo assim, se transportar como ferramenta para vivência do lazer, o que pode fazer sentido ao usuário dentro de seu contexto social. Porque para a definição compreendida dentro da temática de Caillois, podemos fazer uma breve passagem perpassando as possibilidades de tais posturas citadas pelo autor, possam ser compreendidas, ou surgirem como um pequeno passo inicial para que se faça uma observação menos preconceituosa e mais inserida, do lazer como possível espaço para atitudes patológicas, que não só aquelas compreendidas superficialmente.

Considerando a perspectiva da droga inserida nas vivências de lazer, é possível uma aproximação onde, através dos questionamentos anteriores, (lazer, sociedade e escolha), entende-se ser, assim como outras manifestações vivenciadas, observadas e categorizadas em Caillois, uma manifestação cultural como outras passíveis de tal

\footnotetext{
${ }^{7} \mathrm{Na}$ definição de Roger Caillois, o jogo possui possibilidades cujo autor entendeu categorizar de acordo com suas características, em quatro categorias. Tais categorias (Agôn, Alea, Mimicry e Ilinx), e os jogos nelas categorizados, são passíveis de uma progressão análoga, que os hierarquiza em dois pólos antagônicos, Paidia e Ludus.
} 
categorização. A droga, nesta perspectiva, surge então como possibilidade (não apropriada, mas a ser considerada), dentro das vivências do usuário nesse espaço/tempo.

Para justificar tais argumentos, e para ampliar o espectro deste estudo, além daquilo que deseja questionar, Dumazedier (2003, p.11-16) colabora no sentido de demonstrar como tal abordagem faz-se necessária e compreende parte importante do entendimento sobre a droga inserida socialmente, além da abordagem fisiológica recorrente:

A maioria dos documentos sobre o fenômeno, relatado por médicos, carece de base científica. Entretanto, é a eles que dão crédito os homens políticos, educadores e pais. Isso não quer dizer que não haja médicos capazes de tratar os viciados em drogas pesadas. Não me refiro ao tratamento, falo simplesmente do conhecimento sociológico do fenômeno, das suas dimensões, do seu significado. Para tratar tal problema, um médico não é mais qualificado que um engenheiro, um operário ou um comerciário.

Porque ao levantar o questionamento da droga, e ao perpassá-la por uma leitura do lazer, não abrimos mão de importantes facetas dos estudos já aprofundados nesta questão, como as implicantes fisiopatológicas já citadas. Tais estudos vêm se constituindo ao longo dos anos como base para a constatação de aprimorarmos nosso olhar sobre a presença das drogas em outras esferas que não delegá-las a marginalidade de um grupo dissociado do ator socialmente inserido. E é justamente porque tais facetas são aprofundadas e divulgadas, cabe pontuar no sentido de verificar a presença da droga no lazer, possível ou não, no entanto, perceptível, para que seja viável explorar outros desdobramentos do uso de drogas no contexto deste estudo. A possibilidade é a de aplicar uma lente menos pontuada por pré-classificações, com a intenção de trazer novas constatações sobre a manifestação da droga em outras facetas da sociedade. Ainda que não haja uma regra que determine esta característica, busca-se a soma do 
conhecimento adquirido, ás necessidades de conhecimento percebidas ao longo dos estudos. Ainda em Dumazedier, (2003, p.11-16):

[...] na realidade, encontramo-nos diante de um fenômeno social, sóciocultural, e a escola, a universidade, quase nunca o mencionam a não ser para proibir, para reprimir, para mostrar o "mal". Mas, de modo geral, não se dá formação para o prazer, para fazer entender os problemas do lazer, para analisar as atividades que podem ocupar o lazer, não se dá formação alguma sobre as drogas de recreio, os prazeres que podem trazer o seu uso moderado para alguns e os perigos exatos que acarreta seu uso imoderado. Quando se fala, não se diz à verdade, mente-se, nossa ciência está falsificada. E os jovens não são enganados. Uma educação ignorante, hipócrita, de nada adianta.

E, brevemente, ao traçar um paralelo entre lazer e prazer, podemos compreender de maneira mais clara toda trama envolvida nestas facetas complexas e bastante ricas. Porque foram levantadas características de uma sociedade na qual o lazer e a droga se inserem, perpassam e mais do que coexistem, interexistem. Lazer delineado de tal maneira que, ainda que se deva acreditar e intervir para que seja ambiente de construtos críticos e criativos, é manifestação fruto de um produto de trabalho e cada vez mais associado ao potencial de "capitalização" do seu meio de produção. Portanto, mais ou menos acessível, para uns que para outros. Mais ou menos palpável para este ou aquele indivíduo.

E sendo desta forma, o lazer migra de sua conceituação idealizada, para um aspecto bastante subjetivo: este lazer que tratamos acima, nem todos podem ter. Nem todos podem vivenciar, nem todos podem participar. Fica clara então a intenção de Dumazedier ao denominar "hipócrita", a educação que repete os vícios da sociedade, sem questioná-la.

Segundo Baudrillard (1995, p.35), a conseqüência de tal postura social perante a produtividade e o lazer pode ser considerada a seguir: 
[...] A pressão psicológica e social da mobilidade, do estatuto, da concorrência a todos os níveis (rendimento, prestígio, cultura, etc.) torna-se cada vez mais pesada para todos. Necessita-se de mais tempo para se recriar e reciclar, para recuperar e compensar o desgaste psicológico e nervoso causado por múltiplos danos: trajeto domicílio/trabalho, superpopulação, agressões e stress contínuos. Em última análise, o preço mais elevado da sociedade de consumo é o sentimento de insegurança generalizada que ela engendra...

E é neste sentimento de insegurança que a droga pode surgir no espaço/tempo de lazer. Não porque especificamente a droga seja ocupação ou ferramenta para abarcar os medos e anseios de uma sociedade que cobra do indivíduo produzir para uma necessidade que ela mesma institui. Mas porque através dessa trama impregnada de valores que não partem especificamente de uma necessidade intrínseca de realização pessoal do ator social, a droga parece contemplar tais carências ou contestações.

Neste sentido, a proposta de uma análise biopsicossocial destas manifestações parece pertinente. Porque na esfera social, encontra-se o lazer, suas manifestações e vivências. O sujeito que o vivencia é viabilizador de mudanças, criações e recriações no âmbito do lazer. E a droga pode surgir como um contraponto entre este sujeito e seu espaço de ação (neste caso, o lazer), ao mesmo tempo em figura como o objeto de encontro entre as partes deste estudo. Como explica Elias, (1992, p.164):

O estudo do lazer, como dissemos, é um dos numerosos casos em que não é possível descurar o problema da relação entre os fenômenos do nível social e os que se encontram nos níveis psicológico e fisiológico. A este respeito, não se pode evitar o trabalho de uma análise múltipla dos níveis, isto é, o de considerar, pelo menos em traços gerais, como é que no estudo do lazer os três níveis - sociológico psicológico e biológico - se relacionam.

No relevante a importância da análise do consumo de drogas ilícitas associada ao lazer, é possível afirmar que através destas vivências, ainda que severamente impregnadas dos conteúdos característicos da sociedade contextualizada e atual 
(retoma-se aqui o caráter "comercial" do lazer), possivelmente ainda constituem em momento oportuno para uma constatação mais aprofundada de nuances menos evidentes, em uma sociedade marcada pelas "poucas oportunidades para manifestações coletivas de sentimentos intensos". (Elias e Dunning, 1992, p.72).

Segundo Giacomello e Reis, (2005, p.5):

É possível afirmar que as atividades de lazer [...] devido ao alto grau de relevância que possuem no contexto social, sejam caminhos extremamente importantes e interessantes para a compreensão das relações existentes em nossa sociedade... Entender porque as pessoas buscam as atividades de lazer e perceber o processo das mesmas enquanto geradoras de emoções colabora para o entendimento das relações humanas e as suas evoluções.

Desta forma, o caminho no sentido de verificar as possíveis relações da presença das drogas no lazer, delineia-se por entender a droga como manifestação individual, porém sempre considerando o indivíduo inserido no contexto das relações sociais. E estando inserido inevitavelmente neste contexto, interfere na construção e crescimento desta sociedade. Longe de julgar ou identificar posturas como certas ou erradas neste comportamento, (é sabido que o uso das drogas ilícitas compõe um caminho perigoso e muitas vezes mortal), busca-se então, identificar neste caminho (busca, atitude, postura), sua intencionalidade e o que ela pode proporcionar em contraponto a outras atividades prazerosas, arriscadas e desafiadoras, que não o uso de substâncias ilícitas.

Seriam as drogas um caminho mais rápido e eficaz de liberar tensões e restaurar novas através de excitações agradáveis? Se for possível afirmar que sim, devemos assumir a necessidade dessas tensões, e o espaço que o lazer proporciona para tal. Gebara, (2002, p.85) explica a necessidade humana de vivenciar estas tensões, e como elas se equilibram:

As relações entre lazer e o não-lazer tornam-se um equilíbrio entre tensões flutuante. A função do lazer, se é que assim podemos nos 
expressar, não é liberar tensões compensatórias e sim, restaurar tensões agradáveis e desrotinizadoras, capazes de recuperar e integrar todas as esferas da vida.

Cabe então salientar que, ao levantar o questionamento deste estudo, o norteador inicial está no campo das relações. E como citado anteriormente, relações que serão observadas em uma perspectiva biopsicossocial. Relações interindivíduos, entre o indivíduo e a sociedade, entre o indivíduo e a droga. Verificar de maneira pertinente, se o tempo entendido como de lazer pode proporcionar a existência dessas relações, e como o usuário entende seu tempo de lazer, no entanto, considerando a possibilidade de que este espaço/tempo, não se constitua como efetivo espaço para este uso. A busca deste estudo é, então, verificar qual a função exercida pela droga para contemplar o que o usuário entende como "tempo de lazer".

Parte-se então da busca pela compreensão da necessidade deste tempo, independente, inicialmente, de quais vivências serão exercidas por quem usufrui deste lazer. Giacomello e Reis, (2005, p.5), colocam algumas possibilidades para o entendimento desta questão:

Entender porque as pessoas buscam as atividades de lazer e perceber o processo das mesmas enquanto geradoras de emoções colabora para o entendimento das relações humanas e as suas evoluções [...] O prazer vivenciado nestas práticas propicia um efeito catártico, renovando e restaurando o corpo e a mente. As recentes atividades que se incorporaram ao leque de opções de lazer, como os esportes "radicais" também parecem ser a busca por emoções mais fortes.

E dentro daquilo que contempla estas necessidades, o indivíduo busca estabelecer-se. De certa forma, estabelecer-se socialmente, implica em conduzir ações para o prazer de sentir-se socialmente inserido, capaz, reconhecido. E ainda assim, poder satisfazer necessidades pessoais de prazer, desejos e liberdade. O limite para a complexa realização destes anseios pode parecer muito óbvio se aplicado às regras 
sociais, no entanto tem um entorno bastante complexo quando se considera o indivíduo sob a pressão das posturas que se entendem por "socialmente aceitas e corretas". Romera, (2008, p. 77), explica esta relação:

Nesse sentido, os controles desenvolvidos nas sociedades modernas, que provocam por um lado certa restrição da demonstração de sentimentos podem provocar, por outro lado, a busca por válvulas de escape para a livre expressão dessas mesmas emoções reprimidas.

Tem-se então delineados, diversos fatores que constituem o lazer contextualizado neste estudo. Mesmo que traga consigo algumas pretensões de sociedades menos complexas, porque esteve presente nos mais diversos momentos desde o entendimento da perspectiva de civilização, e que ainda seja encarado rançosamente por este ou aquele braço de poder que delega valor inferior a sua presença e necessidade neste contexto atual, o lazer é absolutamente componente irredutível das relações sociais, que são base da evolução de uma sociedade. Romera, (2008, p. 78) explica:

A dificuldade de aceitação do prazer vivido no tempo livre, caracterizado como tempo de lazer, ou ócio, tem causado, desde a antiguidade, certo temor à sociedade, e principalmente aos seus dirigentes, políticos e religiosos. Influências dos dogmas religiosos, que sempre visaram ao controle do homem, de suas emoções e pensamentos, de seus desejos e de sua liberdade... Assim como, também, por influência da visão capitalista que valoriza produção e consumo de bens, numa sociedade na qual o ser humano é medido e avaliado pela posição profissional, e conseqüentemente social, que ocupa as atividades vivenciadas no campo do lazer, e especialmente aquelas praticadas pelo público jovem e distantes da filosofia capitalista, tornam se alvos de crítica, temor e incompreensão e, portanto, proibição, concretizando uma visão reducionista do lazer.

Ficam então, caracterizados, pontos importantes sobre a tríade aqui proposta. Seja ela compreendida através do olhar biopsicossocial proposto, (lazer, droga, usuário), ou de forma mais subjetiva, (lazer, sociedade, escolha), o componente que proporcionará os desdobramentos no sentido de verificar a apropriação dos 
questionamentos levantados, se dá na esfera do lazer e suas apropriações. Desta forma, é possível caminhar para uma reflexão no sentido de compreender a presença da droga na sociedade, sempre confrontado com as referências neste tema, buscando dissociá-las de preconceitos. Mais do que pano de fundo da presença da droga no cenário social, o lazer é ferramenta importante para compreensão dos valores do usuário sobre a sociedade que compartilha e ajuda a (des)construir.

\section{REFERÊNCIAS}

BAUDRILLARD, J. A Sociedade de Consumo. Lisboa: Edições 70, 1995.

BURNS, E.J. Freud, Cocaína e a sua Noiva., (2002). Disponível em: http://www.rubedo.psc.br/artigosb/frdcocai.htm . Acesso em: 06 jan. 2011.

CAILlOIS, R. Os Jogos e Homens: A máscara e a vertigem. Tradução José Garcez Palha. Lisboa: Ed. Cotovia, 1990.

DUMAZEDIER, J. As drogas e a revolução social do lazer. Licere, Belo Horizonte,v.6, n.2, p. 11-16, 2003.

ELIAS, N. The Civilizing Process: Sociogenetic and Psychogenetic investigations. Massachusetts: Blackwell, 2000.

ELIAS, N.; DUNNING, E. A Busca da Excitação. Lisboa: Difel, 1992.

GEBARA, A. Sociologia Configuracional: as emoções e o lazer. In: BRUNHS, H.T.: Lazer e Ciências Sociais: Diálogos Pertinentes. São Paulo: Chronos, 2002.

GIACOMELLO, S.L.; REIS, H.H.B. A Busca da Excitação no lazer. SIMPÓSIO INTERNACIONAL PROCESSO CIVILIZADOR, 9, 2005. Anais... Ponta Grossa: Tecnologia e Civilização, 2005.

GURFINKEL, D. O episódio de Freud com a cocaína: o médico e o monstro. In: Revista Latinoamericana de Psicopatologia Fundamental: São Paulo, v. 11, n. 3, p. 420-436, set. 2008.

LANDINI, T.S. A Sociologia Processual de Norbert Elias. SIMPÓSIO INTERNACIONAL PROCESSO CIVILIZADOR, 9, 2005. Anais... Ponta Grossa: Tecnologia e Civilização, 2005.

LA MENDOLA, S. O sentido do risco. In: DIAMANTI, I. (Org.). A geração invisível. Milão: II sole 24 Ore, 1999. 
LEFEBVRE, H.A. A vida cotidiana no mundo moderno. São Paulo: Ática, 1991.

MARCELLINO, N.C. Estudos do Lazer - uma introdução, Campinas: Autores Associados, 1996. Coleção educação física e esportes.

Lazer e Educação. 4.ed. Campinas: Papirus, 1998.

2000

Estudo do Lazer: uma introdução. 2. ed. Campinas: Autores Associados,

. Algumas aproximações entre Lazer e Sociedade. Animador Sociocultural: Revista Iberoamericana, v.1, n.2, mai/ set. 2007.

PARKER, S.A. A Sociologia do Lazer. Rio de Janeiro: Zanhar, 1969.

. A Sociologia do Lazer. Rio de Janeiro: Zanhar, 1978.

RIESMAN, D. A multidão solitária. São Paulo: Perspectiva, 1975.

ROJEK, C. Deviant Leisure: The dark side of free-time activity. In: Jackson, E.L.; BURTON, T.L. (Ed.) Leisure Studies: prospects for the twenty-first century. Pennsylvania: Venture Publishing, 1999.

ROMERA, L.A. Juventude, lazer e uso abusivo de álcool. Tese (Doutorado) Faculdade de Educação Física, Universidade Estadual de Campinas, Campinas: [s.n], 2008.

\section{Endereço dos Autores:}

Daniella Marchese

Avenida Dois, 796 / Centro

13500-410 - Rio Claro - SP

Endereço Eletrônico: dani.marchese@ gmail.com

Guanis de Barros Vilela Junior

Universidade Metodista de Piracicaba

Faculdade de Educação Física

Rodovia do Açúcar, km 156

13400-911 - Piracicaba - SP

Afonso Antônio Machado

Universidade Estadual Paulista

Secretaria do DEF / IB

Av. 24 - A, 1515 / Bela Vista

13506-900 - Rio Claro - SP 